Jaqueline Esther

Schiavoni

UNESP - Universidade Es-

tadual Paulista. São Paulo,

SP, Brasil.

\section{Narcos: estratégias de publicidade e propaganda}

Narcos: advertising and marketing strategies

\author{
Narcos: estrategias de \\ publicidade y marketing
}




\section{RESUMO}

Otrabalho busca explicitar algumas das estratégias de publicidade e propaganda presentes em material divulgado pela Netflix - teasears, trailers e vinhetas - a fim de promover a primeira temporada da série Narcos. $O$ estudo se vale da teoria das modalidades desenvolvida no âmbito da semiótica francesa e apresenta como resultado que, tomadas em conjunto, tais peças comunicam ao enunciatário todas as competências necessárias - virtualizantes e atualizantes - para que ele assista ao conteúdo dessa série original, por meio de assinatura, e assim contribua para o êxito financeiro da Netflix.

Palavras-chave: Netflix. Narcos. Semiótica francesa. Teoria das modalidades.

\section{ABSTRACT}

This paper seeks to clarify some of the advertising and marketing strategies presents in the material published by Netflix - teasears, trailers and vignettes - to promote the first season of Narcos series. The study makes use of the modality theory developed under the french semiotics and has as a result that, taken together, these pieces communicate to the enunciatee all the necessary competeces - virtual and atual - so he watch the contents of the original series through subscription, and contributes to the Netflix financial success.

Key-words: Netflix. Narcos. French semiotics. Modality theory.

\section{RESUMEN}

El trabajo pretende aclarar algunas de las estrategias de publicidad y marketing presente en el material liberado por Netflix - teasears, trailers y viñetas - para la promoción de la primera temporada de la serie Narcos. El estudio hace uso de la teoría de las modalidades desarrolladas bajo la semiótica francesa y tiene como resultado que, en su conjunto, estas piezas comunican al enunciatario todas las habilidades necesarias -virtualizantes y atualizantes - para disfrutar el contenido original de la serie a traves de ls suscripción, y contribuir así al éxito financiero de Netflix.

Palabras claves: Netflix. Narcos. Semiótica francesa. Teoría de las modalidades. 


\section{Introdução}

Os serviços de conteúdo audiovisual sob demanda - como filmes, séries, documentários e shows - têm despertado um interesse crescente na sociedade atual. Para se ter ideia, a Netflix, empresa representativa nesse mercado, chegou a alcançar a marca de 62,3 milhões de assinantes em 2015, e seu valor na bolsa (US\$ 32,9 bilhões) superou o da CBS (US\$ 30,6 bilhões), terceira maior emissora de televisão aberta do mundo (MOURA, 2015, p. 41).

De modo diferente do que ocorre no modelo de negócios da televisão, no modelo sob demanda os produtos ficam todos dispostos num servidor on-line e podem ser buscados, selecionados, fruídos e em alguns casos arquivados pelo usuário, a qualquer hora e de qualquer lugar, por meio de variados dispositivos midiáticos - a própria televisão, mas também o computador, o videogame, o celular etc. Nessa perspectiva, Paula Silva e Thayná da Silva (2013) diferenciam três modelos ou propostas existentes nos dias de hoje:

Transactional VOD (TVOD): é o modelo em que o usuário paga por transação, podendo comprar ou alugar a mídia. No caso de aluguel, ao realizar o pagamento, o usuário compra o direito de visualização do conteúdo por um período de tempo determinado, geralmente um ou dois dias. No caso de compra, o usuário realiza o download do conteúdo e o armazena em seu disco rígido; Subscription VOD (SVOD): neste modelo de 
comercialização o usuário paga uma taxa periódica (mensal, anual, etc. dependendo de cada pacote), para ter acesso ilimitado a um acervo. Assim, o usuário compra o direito de visualizar todo o conteúdo de um catálogo quantas vezes desejar durante o tempo que durar a assinatura paga. Um caso especial de SVOD é de operadoras de TV por assinatura que possuem uma plataforma com acervo disponível sem custo adicional para seus clientes (assinantes), porém, assume-se que o valor da taxa da SVOD está incluído na assinatura, não sendo um serviço gratuito; Free On Demand (FOD): esse modelo disponibiliza um acervo de filmes grátis para os usuários, basta se cadastrar no site. A receita vem de propagandas no próprio site e no início do filme (SILVA; SILVA, 2013, p. 19-20, grifos do autor).

Embora os modelos de pagamento por transação e por assinatura se mostrem capazes de viabilizar o serviço por demanda como um negócio lucrativo - como vimos no caso da Netflix - vencido esse primeiro desafio, que é o do modelo de negócios, resta ainda outro, talvez até maior: como levar o público à efetivação da transação unitária ou a adesão por assinatura? Tem-se aqui uma questão de manipulação. Segundo Greimas e Courtés, "a manipulação caracteriza-se como uma ação do homem sobre outros homens, visando a fazê-los executar um programa dado: no primeiro caso, trata-se de um 'fazer-ser', no segundo, de um 'fazer-fazer'" (1979, p. 269, verbete manipulação). De modo que a resposta à questão que colocamos parece poder ser contemplada, ao menos em parte, com o auxílio da teoria das modalidades desenvolvida no âmbito da semiótica francesa?.

Segundo Calbucci, "Greimas apresenta o conceito de modalidade no artigo "Pour una théorie des modalités", publicado, em 1976, na revista Langages, e, depois, no volume Du sens II (1983). Entre as duas publicações desse artigo, o primeiro Dicionário de semiótica (GREIMAS; COURTÉS, 1979) dava grande atenção a esse conceito" (CALBUCCl, 2009, p. 70). 
Vale recordar então "o papel excepcional que desempenham, na organização semiótica dos discursos, os valores modais querer, dever, poder e saber, capazes de modalizar tanto o ser quanto o fazer" e "os níveis de existência - existência virtual, atual, e realizada -, que constituem outras tantas instâncias que balizam um percurso -interpretável como uma tensão (G. GUILLAUME) - que vai de um ponto zero à sua realização" (GREIMAS; COURTÉS, 1979, p. 283, verbete modalidade).

Para a semiótica de base greimasiana, os termos virtual, atual e real estão ligados aos modos como um sujeito e um dado objeto-valor se mostram em relação:

Anteriormente à sua junção, sujeitos e objetos estão em posição virtual. Com a função juntiva - e no quadro dos enunciados de estado -, dois tipos de relações se instauram: ou há disjunção entre sujeitos e objetos, e, nesse caso, dir-se-á que estes estão atualizados, ou então há conjunção, e eles se encontram realizados. Entender-se-á, pois, por realização a transformação que, a partir de uma disjunção anterior, estabelece a conjunção entre o sujeito e o objeto (GREIMÁs; COURTÉS, 1979, p. 371, verbete realização).

Assim, tomando-se em consideração o percurso tensivo que leva à realização, os valores modais podem ser agrupados da seguinte maneira:

Quadro 1: Modalidades

\begin{tabular}{|c|c|c|c|}
\hline Modalidades & Virtualizantes & Atualizantes & Realizantes \\
\hline exotáxicas & Dever & poder & fazer \\
\hline endotáxicas & Querer & saber & ser \\
\hline
\end{tabular}

(GREIMAS; COURTÉS, 1979, p. 283.) 
A partir disso, é possível traçar as estratégias de modalização das empresas, pois, antes da realização, ou melhor, para que se estabeleça a conjunção entre um sujeito e um dado objeto de valor, será necessário trabalhar tanto os valores modais virtualizantes (querer/ dever) como os atualizantes (saber/poder). Caberá à análise o reconhecimento das escolhas feitas pela instância da enunciação, isto é, das estratégias utilizadas. Mas, antes de assim proceder - quer dizer, de proceder às análises dos enunciados - convém observar e sistematizar a própria ação que se coloca em curso:

Na tradição filosófica que remonta à escolástica, entende-se por ato 'o que faz ser': o agir identifica-se, assim, ao 'fazer-ser' e corresponde à passagem da potencialidade à existência. Tal definição, cujo caráter intuitivo se percebe, possui uma grande generalidade: não só 'todos' os acontecimentos que constituem a trama dos discursos narrativos se deixam interpretar como atos, mas o próprio discurso constitui um ato, uma sequencia organizada de atos cognitivos. Em consequência, é indispensável dispor-se de um modelo de representação do ato, que possa ser utilizado na análise semiótica e possa, eventualmente, servir de ponto de partida para uma semiótica da ação (GREIMÁs; COURTÉS, 1979, p. 31, verbete ato).

Temos, então, que o objetivo das empresas comerciais de vídeo sob demanda $\left(\mathrm{S}_{2}\right)$, por meio de suas ações publicitárias (F), é alcançar o êxito financeiro $\left(\mathrm{O}_{2}\right)$. Esse pode ser considerado seu programa narrativo de base. Para isso, deverá modalizar o enunciatário $\left(S_{1}\right)$ a fim de que este entre em conjunção com os conteúdos audiovisuais que oferece $\left(\mathrm{O}_{\mathrm{v} 1}\right)$ - e pelos quais pagará para ver. Esse pode ser considerado seu programa narrativo de uso. Assim, o modo como o ato se mostra organizado, pode ser representado na seguinte estrutura: $\mathrm{F}\left[\mathrm{S}_{2} \rightarrow \mathrm{O}_{\mathrm{v} 2}\left(\mathrm{~S}_{1} \cap \mathrm{O}_{\mathrm{v} 1}\right)\right]$, em que: 
$\mathrm{F} / \rightarrow=$ função publicitária

$\mathrm{S}_{2}=$ empresa

$\mathrm{O}_{\mathrm{v} 2}=$ êxito financeiro

$\mathrm{S}_{1}=$ enunciatário

$\mathrm{O}_{\mathrm{v} 1}=$ conteúdos por transação ou assinatura

[ ] = enunciado de fazer

() = enunciado de estado

Isso significa que:

...do ponto de vista da posição sintagmática ocupada na representação do encadeamento das atividades humanas, o enunciado modal factivo se apresenta como um 'fazer ser', isto é, como uma performance cognitiva do sujeito $S_{2}$; como tal, esse enunciado está naturalmente apto a se desenvolver como um programa cognitivo em expansão (assim, 'fazer crer' se articula como um programa de fazer persuasivo). Mas, ao mesmo tempo, o objeto visado por essa performance cognitiva é a virtualização da competência pragmática, implicitamente reconhecida, do sujeito $S_{1}$ (GREIMAS, 2014, p. 87).

Com isso, é possível chegar a uma representação sintagmática das quatro estruturas modais que acabamos de ver na citação anterior, esboçada pelo próprio Greimas (2014, p. 87):

$$
\begin{aligned}
\text { performance cognitiva de } S_{2} \downarrow & \downarrow \text { competência cognitiva de } S_{2} \\
\text { competência de } S_{1} & \text { performance de } S_{1}
\end{aligned}
$$

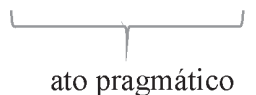


Diante do arranjo que acabamos de montar, é possível notar, como bem explicitou seu arquiteto, "o quanto a organização sintagmática do ato se assemelha ao discurso narrativo":

Vê-se que o ato de um sujeito qualquer se encontra como que envolto por instâncias modalizantes de um segundo sujeito situado na dimensão cognitiva. As duas estruturas modais envolventes são, do ponto de vista sintático, pressuponentes e não pressupostas: para se efetivar, a performance de $S_{2}$ pressupõe a competência de $S_{1}$, cuja performance é, em seguida, pressuposta pela competência de $S_{2}$. $O$ ato de $S_{1}$, mesmo bastando a si próprio, pode se inserir, sob certas condições, no percurso cognitivo translativo. / Nota-se, nesse momento o quanto a organização sintagmática do ato se assemelha à do discurso narrativo, ou antes ao programa narrativo canônico: este, articulado em duas componentes, competência e performance, refere-se geralmente à instância do destinador, encarregado, primeiro, de outorgar um mandato ao sujeito e, em seguida, de sancioná-lo (GREIMAS, 2014, p. 88).

Estabelecidos os programas interdependentes que estruturam a ação da empresa sobre o público, passemos às estratégias colocadas em discurso. Para tanto, iremos utilizar como exemplo de análise algumas das peças de divulgação e promoção - teasers, trailers e vinhetas - de uma obra audiovisual feita para ser disponibilizada sob demanda, como conteúdo original: trata-se da série Narcos, em sua primeira temporada, produzida para a Netflix, uma empresa de vídeos sob demanda por assinatura.

Essa escolha leva em consideração que, diferentemente de outros títulos disponíveis no servidor, a série Narcos não era conhecida pelo público, não constava na memória individual ou coletiva por conta 
de experiências de visualização e ou de publicidade anteriores, pois não havia sido transmitida em outras mídias (como televisão, cinema, DVDs etc.). De modo que as ações publicitárias tiveram de ir "do ponto zero à realização" (GREIMAS; COURTÉS, 1979, p. 283, verbete modalidade). Isto é, da atribuição de valores modais ao público, num processo de manipulação que visa tornar o sujeito competente para a ação a ser realizada, à ação em si, ou seja, a performance desse sujeito competente na aquisição de valores descritivos, no caso, o conteúdo audiovisual.

\section{Teasers e trailers}

O termo teaser provém do verbo inglês to tease, que significa provocar (MICHAELIS UOL). No âmbito da indústria audiovisual, sua aparição tem por objetivo despertar a atenção do público-alvo para um produto a ser ainda lançado. Nesse tipo de peça, como evidenciaremos logo adiante, costuma-se proceder com a tática de ao mesmo tempo "mostrar e esconder", criando um efeito de tensão sobre o público, isto é, de espera - senão pelo objeto anunciado ao menos por informações adicionais.

Para que esse efeito seja alcançado, é preciso considerar minuciosamente as características tanto do objeto anunciado como do público ao qual se dirige. No primeiro caso, esse exercício permitirá transpor para o discurso as características fundamentais do produto em questão. E, no segundo, adequar tais características, tanto quanto possível, ao público pretendido. 
Figura 1 - Teaser Netflix - EUA ${ }^{2}$

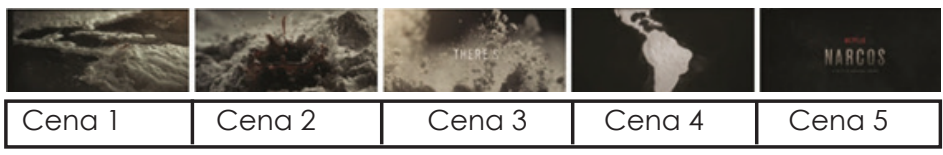

No caso dos teasers da série Narcos, o uso de figuras visuais como a "gota de sangue" que cai sobre um amontoado revolto de "pó branco", dando forma ao desenho geográfico da "América Latina" associadas a figuras sonoras não-diegéticas de "instrumentos de percussão" parecem suficientes para conferir à trama a ser lançada certo tom dramático, indicando que a narrativa conjugará violência, uso e produção de drogas na América Latina. O texto verbal "Narcos", abreviação de narcotraficante, indica o caráter monetário que perpassará a história.

Se esses elementos ou figuras do nível discursivo conseguem nos situar em relação à temática da série, o mesmo não se pode dizer em relação ao direcionamento de público. No exemplo abordado, esse viés é trabalhado por meio do slogan que aparece em texto verbal escrito no decorrer do vídeo. Na versão para os Estados Unidos e Canadá: "There's no business like blow business". Na versão para o Brasil": "O sucesso virou pó".

Essas escolhas, de custo relativamente baixo em termos de produção - pois não foi preciso construir um teaser diferente para cada público, apenas mudar o texto que nele é inserido -, carregam, respectivamente, valores disfóricos e eufóricos próprios

2 Teaser disponível em: https://www.youtube.com/ watch?v=JvCWrIWMW24. Acesso em: 05/10/2018.

3 Teaser disponível em: https://www.youtube.com/ watch? $v=h n b y U X W 1 T i A$. Acesso em 05/10/2018. 
para cada uma das culturas mencionadas. No primeiro caso, a palavra blow pode ser vertida como 1) "soco", "golpe", "pancada"; 2) "calamidade súbita", "desgraça repentina", "desastre", "ataque repentino", "assalto"; e 3) "sopro", "corrente de ar", "encher de ar" (MICHAELIS UOL). Assim, para a nação que viu o mercado da cocaína crescer vertiginosamente em seu território sem Ihe dedicar um único centavo ao mesmo tempo em que fazia crescer os índices de violência no país, a escolha pelo termo blow deixa latente, em todas as acepções possíveis, um sentido de disforia para o narcotráfico. No segundo caso, isto é, do teaser destinado ao Brasil, embora a frase também seja construída de maneira ambígua, os sentidos latentes como "o pó é um sucesso", "o pó leva ao sucesso" ou mesmo "o sucesso do pó acabou" trazem uma carga eufórica considerável ao abordar o tema. Diferente da versão estadunidense, a ênfase aqui não está nos efeitos do tráfico, mas em como se construiu uma história de fama com a droga.

Com esses elementos, o teaser nos faz saber 0 tema a ser trabalhado, mas não nos informa, por exemplo, de que história especificamente se trata, quem serão os personagens, qual será o estilo de filmagem, e outros detalhes. Nenhuma cena do filme é dada a ver. Por isso, como já afirmado, é um tipo de produção que ao mesmo tempo "mostra e esconde": mostra o tema, mas esconde as escolhas narrativas que serão colocadas em discurso.

Com o trailer, a estratégia ganha uma nuança diferente: "revelar algumas partes, mas nunca o todo". No dicionário em português, a palavra é definida como "exibição de recortes de filme montados descontinuadamente, a fim de, sem lhe revelar 
o entrecho, despertar a curiosidade do espectador" (MICHAELIS UOL). A montagem descontínua, da qual trata o verbete, nos remete a saltos no tempo cronológico da história. Trata-se, portanto, de uma descontinuidade temporal tendo em vista que a história deve ser apresentada de modo resumido a partir de suas próprias imagens - cenas, diálogos etc. Quanto ao entrecho, que não deve ser revelado, este é constituído pelos elementos narrativos que permitirão à história se desenrolar. De modo que a construção do trailer poderá recair sobre o quê ou mesmo quem, quando ou o porquê das coisas que ocorrerão, mas nunca sobre como as ações da trama irão se desenvolver. Este último será o ponto pelo qual o público esperará para ver, todos os demais serão elementos de variação para instigá-lo a tanto.

Isso significa que um filme ou série poderá valerse de diferentes materiais de promoção, isto é, trailers com diferentes construções e ênfases de sentido para uns o quê, para outros por que e assim por diante - a fim de despertar a atenção do público para o qual se dirige. Para exemplificar como isso foi feito em Narcos, foram comparados os trailers produzidos para o Brasil ${ }^{4}$, América Latina 5 e Estados Unidos 6 .

No primeiro, dando continuidade à proposta lançada no teaser - "o sucesso virou pó" -, o material produzido para o Brasil enfatiza a história de um homem nascido em uma família pobre, num país pobre e que antes de alcançar os 30 anos de idade chegou

\footnotetext{
4 Trailer disponível em: https://www.youtube.com/ watch? $v=U L U K K T 25 K e A$. Acesso em 05/10/18.

5 Trailer disponível em: https://www.youtube.com/ watch? $v=$ OvefmTHrfLk. Acesso em 05/10/18.

6 Trailer disponível em: https://www.youtube.com/watch?v= mEkOigEOws. Acesso em 05/10/18.
} 
a ter mais dinheiro do que era capaz de contar: o anti-herói Pablo Emílio Escobar Gavíria.

Para o público do restante da América Latina, incluindo a Colômbia, a estratégia foi outra. A figura de anti-herói desempenhada por Pablo Escobar na versão brasileira tem sua expressão diminuída diante do sonho colombiano que ela encarna - de vida próspera e sucesso empresarial - alcançado, no entanto, por meio do tráfico e da violência. A história é apresentada como ancorada em fatos reais e coloca de um lado os senhores do tráfico e de outro os agentes do DEA-EUA (Drug Enforcement Administration).

Já para o público estadunidense, o trailer de Narcos também manteve a proposta apresentada no teaser - "There's no business like blow business" abordando o mercado da droga como um negócio sujo e destrutivo. A produção coloca em destaque a figura de Nancy, esposa de Ronald Regan, presidente dos Estados Unidos na década de 80, em pronunciamento feito pela televisão: "Diga sim para sua vida. E quando se deparar com drogas, apenas diga não!" A frase ecoa por quase todo o vídeo e as imagens que se seguem figurativizam a guerra que o Estado norte-americano travou contra o cartel de Medelín e Pablo Escobar, considerado o maior criminoso de todos os tempos.

As considerações tecidas sobre tais ações publicitárias - teasers e trailers - nos ajudam a perceber dois aspectos fundamentais da teoria das modalidades que apresentamos no início, quando apontamos o modo como se dá a organização sintagmática do ato de enunciação: o da atribuição de competência semântica e a de doação de competência modal. Nesse sentido, "a atribuição de competência 
semântica está sempre pressuposta na doação de competência modal, pois é preciso que o destinatário-sujeito creia nos valores do destinador, ou por ele determinados, para que se deixe manipular" (BARROS, 2001 , p. 28). Em outros termos, isso significa que o processo de manipulação só poderá efetivamente entrar em curso se houver entre o manipulador e o manipulado o compartilhamento de um sistema de valores e se uma relação de cumplicidade, por assim dizer, se estabelecer entre as partes.

As diferentes ênfases observadas nos teasers e nos trailers, conforme o público ao qual se destinam Estados Unidos, América Latina e Brasil - respondem a esse pressuposto, pois caberá ao destinatário verificar a conformidade dos sistemas de valores apresentados pelo destinador no produto audiovisual com o seu próprio sistema de valores. Com isso, a questão não gira em torno da "verdade", mas do "dizer-verdadeiro" em cada lugar, para cada público:

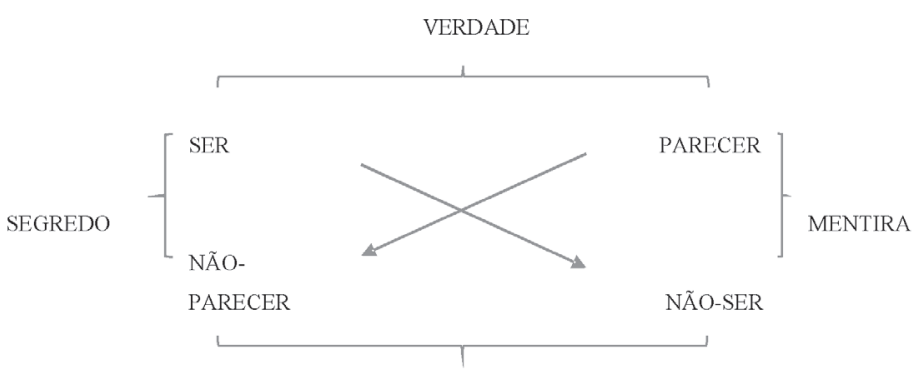

FALSIDADE

A categoria da veridicção, como se pode observar, é constituída pela colocação em relação de dois esquemas: parecer/não-parecer é chamado de manifestação. O do ser/não-ser, de imanência. Segundo Greimas, "é entre essas duas dimensões da existência 
que atua o 'jogo da verdade': estabelecer, a partir da manifestação, a existência da imanência, é decidir sobre o ser do ser" (1979, p. 488). Para a proposta de Narcos, o êxito está em que cada público, em cada lugar, julgue o discurso na relação parecer-ser, atribuindo verdade a ele. Somente assim conseguirá passar para a doação de competência modal, isto é, a manipulação propriamente dita.

Em relação a essa segunda fase, as estratégias de "mostrar e esconder" e a de "revelar apenas algumas partes e nunca o todo" foi instaurando no público o sentido de curiosidade. Em termos modais, a curiosidade pode ser descrita como um querer-saber. Dadas as ações que descrevemos, esse estado passional foi sendo modulado por "um clímax de intensidade e por um máximo de extensidade - um desejo irrefreável de saber tudo" (FIORIN, 2007, p. 13) - que apenas poderá ser alcançado pelo consumo do produto audiovisual. Assim, antes de lançar a série, a Netflix disponibilizou seus teasers e trailers nos espaços que mantém em diferentes redes sociais a fim de modalizar o público - a maior quantidade possível de pessoas - pelo querer: o querer-saber (conhecer a história na íntegra) levando ao querer-fazer (adquirir o direito de consumir o produto). No quadro dos modos de existência semiótica, o querer é uma modalização virtualizante, isto é, constitui-se condição prévia para a transformação do sujeito. A mesma coisa acontece com a modalização pelo dever, que analisaremos no primeiro tópico sobre vinhetas.

\section{Vinhetas}

Em se tratando de produções audiovisuais, as vinhetas se dividem em dois tipos básicos: as que pro- 
movem a marca da empresa e as que promovem seus produtos e/ou serviços (SCHIAVONI, 2015). Visto que possuem objetos distintos e pretendem efetuar diferentes tipos de contrato com o público tendem, em geral, a serem produzidas de maneira independente - cada uma para o seu devido fim. No entanto, nos dois exemplos seguintes que utilizaremos para a análise, a Netflix mesclou as propostas (marca-produto) articulando configurações interdiscursivas-autorreflexivas e intertextuais-autorreflexivas, como abordaremos mais adiante, ao final da apresentação das modalizações que essas produções engendram.

Assim, no primeiro vídeo vemos se desenvolver uma conversa entre dois homens. Estes, em seus figurinos e cenário de atuação, são os personagens Javier Peña e Steve Murphy, os agentes do DEA enviados à Colômbia pelos Estados Unidos para capturar Pablo Escobar. Mas o diálogo que se ouve na vinheta é bem diferente do que se escuta no seriado no decorrer dessa cena. Embora esses aspectos possam escapar ao público que não assistiu a Narcos, é possível assimilar que se trata do trecho de uma série e que este está sendo utilizado para fins de paródia - visto que um desses homens (Steve, à direita do quadro, de cabelos loiros) interpela o colega em falas como "a série está fazendo sucesso pra caramba" e "você está na casseta da série". 
Figura 2 - Vinheta Netflix n. $1^{7}$

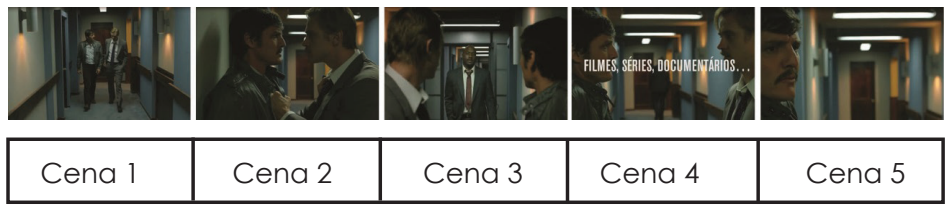

\begin{tabular}{|c|c|}
\hline Cena 1 & $\begin{array}{l}\text { - Então, parece que a série está fazendo sucesso pra } \\
\text { caramba mesmo. Você devia assistir, bicho! } \\
\text { - Supimpa! Em que canal passa? }\end{array}$ \\
\hline Cena 2 & $\begin{array}{l}\text { - Você tá na casseta da série e nem sabe o que é um } \\
\text { original Netflix, brother? Não é um canal! } \\
\text { - O que é Netflix? } \\
\text { - É um serviço de vídeo sob demanda. } \\
\text { - Que porra é essa, bicho? } \\
\text { - Você paga uma mensalidade e pode assistir aos } \\
\text { filmes do catálogo quando e onde quiser. } \\
\text { - Mas isso aí deve ser caro pra chuchu. } \\
\text { - É menos do que você gasta no bar. E o primeiro mês } \\
\text { é grátis. }\end{array}$ \\
\hline Cena 3 & $\begin{array}{l}\text { - Uhuuu! Acabei de acabar o House of Cards. Esse } \\
\text { Underwood é fogo mesmo! }\end{array}$ \\
\hline $\begin{array}{l}\text { Cena } 4 \text { e } \\
\text { Cena } 5\end{array}$ & $\begin{array}{l}\text { - Em que época você vive? Me liga quando assinar } \\
\text { Netflix, seu paspalho! }\end{array}$ \\
\hline
\end{tabular}

As referências que o vídeo apresenta configuram-se imitações burlescas, que nos causam riso. Trata-se, pois, de uma reconfiguração estilística que tende a destituir o objeto-alvo de sua nobreza, simplesmente porque a paródia não se prende a qualquer tipo de convenção artística, social ou moral. Sobre o assunto, Linda Hutcheon argumenta que a deformação intencionada pela paródia não está ligada apenas à subversão. A autora sugere que, para se afirmar diante uma dada tradição cultural, o homem ocidental

7 Vinheta disponível em: https://www.youtube.com/ watch? $v=f 4 P N S w k q o c 8$. Acesso em: 05/10/18. 
tende deliberadamente a desconstruir e reconstruir suas referências, de modo que "a paródia é, pois, repetição, mas repetição que inclui diferença; é imitação com distância crítica [...] e o âmbito de ethos pragmático vai do ridículo desdenhoso à homenagem reverencial" (HUTCHEON, 1989, p. 13 e 54 apud CANO, 2004, p. 85).

Fazendo-nos rir do diálogo que se trava entre os agentes, ou melhor, da situação constrangedora em que se vê Javier (o homem de cabelos pretos e bigode, à esquerda do quadro) - pois, ainda tendo a televisão como modelo de referência na fala "em que canal passa?", é o único que não sabe o que é Netflix apesar de estar em uma das séries que a empresa veicula -, o discurso promove um processo de identificação do público. Em semiótica, entende-se por identificação "uma das fases do fazer interpretativo do enunciatário, quando ele identifica o universo do discurso lou uma parte desse universo com o seu próprio universo" (GREIMAS; COURTÉS, 1979, p. 223-224 verbete identificação). Assim, as modalizações que recaem sobre o personagem no vídeo visam alcançar, na verdade, o público, o enunciatário que assiste a vinheta - especialmente se este, como Javier, ainda não souber o que é Netflix. Pois a comunicação é, neste caso, antes de tudo, um fazer-saber.

Observamos então, por meio das interpelações de Steve sobre Javier, a modalização do sujeito por um "dever-fazer" - como se pode ler nas descrições da fala de Steve a respeito da série em questão, Narcos: "você devia assistir" (Figura 2, descrição da cena 1) e, depois, nos julgamentos que faz acerca de seu colega quando este expõe que não sabe o que é Netflix e, alegando impedimentos de ordem 
financeira, resiste ao serviço de vídeo sob demanda: "em que época você vive?". Tem-se nas duas falas destacadas a criação de uma imagem negativa, de alguém desconexo do tempo e da sociedade em que vivemos - e que para alterá-la deve realizar a assinatura da Netflix. A aspereza do diálogo que se desenvolve no decorrer da sequência se dá em vista de que as falas não são travadas diretamente entre a empresa e o público. Este, porém, é a instância última visada pela vinheta como objeto de comunicação, e o processo de identificação termina por permitir que se desenvolva a modalização do enunciatário pelo mesmo "dever-fazer" que recai sobre o personagem.

Mas, como já dissemos, assim como o "querer", a modalização pelo "dever" é apenas virtualizante, ou seja, pré-condição para a transformação do sujeito. De modo que a vinheta também explora a modalização pelo "poder-fazer", esta sim uma modalização atualizante (como se pode observar no Quadro 1). Em relação à transformação, esse estágio se mostra mais avançado do que o anterior, pois já opera entre o sujeito e o objeto um estado de junção, cujos tipos característicos são a disjunção e a conjunção. Antes, na virtualização, as modalizações pelo querer e pelo dever instauravam um quadro prévio para a transformação. Na atualização, tal transformação já está em curso, operando, porém, um estado de disjunção.

Assim, além de buscar conferir ao destinatário um "dever-fazer", as falas de Steve asseguram a Javier - e ao público, dado o processo de identificação um "poder-fazer". Quando este Ihe apresenta como impeditivo da obtenção dos serviços de assinatura da Netflix a questão financeira, ao dizer que o serviço oferecido "deve ser caro pra chuchu" (Figura 2, des- 
crição da cena 2), Steve responde: "é menos do que você gasta no bar. E o primeiro mês é grátis" (Figura 2, descrição da cena 2). A argumentação gira em torno de um valor relativamente baixo - pois Steve diz "é menos do que você gasta" em vez de "não é mais do que você gasta" - e também do fato de que tal quantia já vem sendo utilizada atualmente para fins de entretenimento - a expressão "você gasta" indica um processo contínuo, no presente -, mostrando, portanto, um "poder-fazer".

A explicação sobre o que é Netflix e como funcionam seus serviços nas falas de Steve, que diz "não é um canal" e "você paga uma mensalidade e pode assistir aos filmes do catálogo quando e onde quiser" (Figura 2, descrição da cena 2) busca instrumentalizar o sujeito para a ação, instituindo para ele um "saber-fazer" - para entrar em conjunção com a fruição dos conteúdos audiovisuais ofertados pela Netflix, que se configuram na narrativa o objeto-valor a ser perseguido pelo sujeito. Essa modalidade - atualizante tal como o "poder-fazer" que já vimos - ganha ainda mais especificidade e detalhamento em outra vinheta, conforme segue: 
Figura 3 - Vinheta Netflix n. $2^{8}$

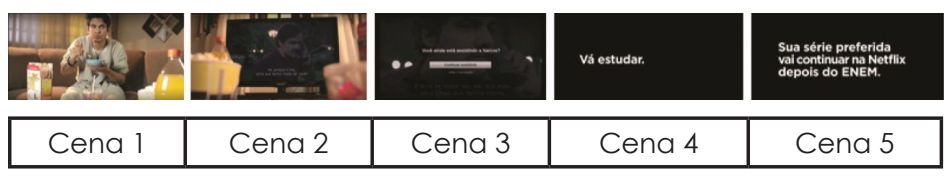

$\begin{array}{ll}\text { Cena } 1 & \text { Usuário assistindo a um dos episódios da série Narcos. } \\ \text { Cena } 2 & \end{array}$

Interpelação do sistema ao usuário.

- Você ainda está assistindo a Narcos?

- Tem certeza?

- Você não devia estudar?

Diálogo entre o usuário e a máquina.

- Peraí, o que é que você sabe sobre a minha vida?

- Mais do que você imagina.

- Que história é essa?

- Sei que você avança a abertura do Sense8.

- Mas é claro, é muito longa!

Cena 3 - Sei que você lutou contra o ar de olho fechado se imaginando o Demolidor.

- É questão de sobrevivência! Vai que eu preciso salvar a Hell's kitchen...

- Sei que sempre tenta ir e voltar do banheiro naqueles 15 segundos.

- E eu quase sempre consigo ir e voltar antes de começar o próximo episódio.

- E sei que você deveria estar estudando pro ENEM.

- Só pra você saber, eu já estudei muito!

- Quem é o presidente dos Estados Unidos?

- É muito fácil, Frank Underwood.

- Risos.

- É O...

Mensagem final da máquina para o usuário.

Cena 4 Vá estudar.

Cena 5 Sua série preferida vai continuar na Netflix depois do Enem.

$8 \quad$ Vinheta disponível em: https://www.youtube.com/watch? $v=W_{-}$ ezqb5hPIA. Acesso em: 05/10/18. 
Observamos no vídeo um dos assinantes da $\mathrm{Ne}$ tflix assistindo a série Narcos. O garoto se mostra dividido entre seu "dever-fazer" (estudar) e seu "querer-fazer" (assistir a Narcos), prevalecendo este o último, já que ele olha para as revistas em cima da mesa (que figurativizam a informação) e o vídeo na tela (que figurativiza o entretenimento) e, ignorando as primeiras, se decide pelo segundo (no trecho entre 0:09 e 0:21). Nesse momento, a fruição é interrompida. E, surpreendentemente, começa a haver um verdadeiro diálogo entre o usuário e a máquina, evidenciando a inteligência do sistema operacional.

Tal estrutura nos coloca diante de dois actantes. Conforme Greimas e Courtés, "os actantes são os seres ou as coisas que, a um título qualquer, ainda a título de meros figurantes e da maneira mais passiva possível, participam do processo" (1979, p. 12, verbete actante). No caso observado, a máquina está longe de ser um "mero figurante". De fato, se apresenta como um destinador que comunica valores modais ao destinatário, o usuário, para que ele cumpra seu programa narrativo: estudar a fim de obter êxito no Exame Nacional de Ensino Médio. Assim, no desenvolvimento do diálogo, a máquina questiona: "você ainda está assistindo a Narcos?" e, diante da afirmativa do usuário, novamente questiona: "você não devia estudar?" (no trecho entre 0:22 e 0:42). Nestas, e em todas as outras interpelações que faz, a máquina apresenta na tela as opções de escolha "continuar assistindo" ou "voltar para a navegação", mostrando ao usuário que ele pode exercer controle sobre os conteúdos que assiste e como fazer isso: basta apertar um botão! - comunicando as modalidades do "poder-fazer" e do "saber-fazer". 
Ao final, o diálogo estabelecido na tela, no âmbito do enunciado, se estende para a esfera da enunciação. Porém, nessa vinheta, isso acontece de modo direto, com a ordem: "vá estudar. Sua série preferida continuará na Netflix depois do Enem" (no trecho entre 1:43 e 1:46). Tal mudança, do plano do enunciado para o da enunciação, é reforçada por uma quebra de continuidade, uma tela preta. A máquina é a mesma do diálogo anterior, mas o interlocutor agora é o enunciatário. Assim, nessa vinheta, torna-se ainda mais explícito o processo de identificação que a empresa busca fomentar entre o garoto da cena e o enunciatário e, por conseguinte, as competências que ela quer comunicar ao público.

É possível perceber, então, que por meio dessas ações publicitárias - teasers, trailers, vinhetas - a Netflix buscou modalizar o público de todas as maneiras possíveis, a fim de alcançar seu objeto de valor, isto é, a adesão do enunciatário como assinante. A disposição de apresentação que seguimos é a mesma que a empresa projetou nas mídias sociais e mostra como ela partiu de modalizações virtualizantes - o querer e o dever - chegando a modalizações atualizantes - o poder e o saber.

As estratégias de interdiscursividade, intertextualidade e autorreflexividade que apontamos antes da análise sobre as vinhetas são estratégias utilizadas para alcançar o objetivo de promover tanto o produto como a marca. Grosso modo, os recursos de interdiscursividade e intertextualidade consistem no processo de, no interior de um texto, fazer referência a outro. A diferença entre os conceitos está em como essa referência é feita: no primeiro caso, o conjunto significante jogará com uma multiplicidade de vo- 
zes, como quando um dos colegas de trabalho dos agentes do DEA-EUA passa por eles, dizendo: "Acabei de acabar o House of Cards. Esse Underwood é fogo mesmo" (vídeo da Figura 2, descrição da cena 3); no segundo, tem-se que uma dada semiótica-objeto é utilizada no interior ou na composição de outra semiótica objeto, como ocorre, por exemplo, com as cenas da série Narcos, as quais o jovem acompanha na tela de seu televisor (vídeo da Figura 3). Nas duas produções observadas, esses recursos garantem a promoção dos conteúdos ou produtos ofertados pela Netflix, num sistema de "alavancagem" - isto é, em que o interesse em um produto pode conduzir o público a também ter interesse em outro produto da mesma marca, aumentando as chances de venda.

Já a função metalinguística ou autorreflexiva chama a atenção para a marca, quero dizer, a empresa e seu modo de funcionamento. Conforme Jakobson, a metalinguagem é uma função centrada no código (2007, p. 127). Assim, voltando-se para o seu próprio modo de estruturação e linguagem, a Netflix usa os personagens de determinada série para falar sobre essa mesma série, que ela pode ser assistida quando e onde quiser (vídeo da Figura 1); e faz um programa de computador interpelar o usuário, interrompendo sua fruição, para dizer que a fruição pode ser interrompida quando o usuário desejar (vídeo da Figura 3). Essas ações dão a conhecer o que é Netflix e o que ela oferece aos seus assinantes.

\section{Considerações finais}

As análises feitas buscaram demonstrar certas estratégias articuladas em algumas ações de publicidade e propaganda desenvolvidas para a primeira 
temporada de Narcos, uma série original Netflix. Tal escolha levou em consideração o fato de que, diferentemente de outros títulos disponíveis no catálogo da empresa, a série Narcos não havia sido transmitida anteriormente, tampouco promovida e divulgada por qualquer mídia. De modo que os teasears, trailers e vinhetas que compuseram o corpus do presente estudo estiveram entre os primeiros gestos nesse sentido.

Assim, buscamos avaliar os processos de manipulação - considerada neste texto, a partir da teoria semiótica de linha francesa, como a "ação do homem sobre outros homens, visando a fazê-los executar um programa dado" (GREIMAS, 1974, p. 269, verbete manipulação) - colocados em discurso. E observamos que, a fim de alcançar a adesão do enunciatário e viabilizar seu modelo de negócios de vídeo sob demanda por assinatura, a Netflix se empenhou em comunicar ao público tanto valores virtualizantes (querer, dever) como atualizantes (poder, saber) visando tornar o sujeito plenamente competente para a ação a ser realizada, isto é, a performance desse sujeito competente na aquisição de valores descritivos, no caso, a fruição do conteúdo audiovisual.

Tais competências modais estão distribuídas de modo diferente nos vídeos. Nos teasers e trailers, que se direcionam exclusivamente para a promoção e divulgação da série Narcos, constatamos haver múltiplas abordagens para contemplar diferentes tipos de público e, analisando peças dirigidas aos Estados Unidos, América Latina e Brasil, percebemos que as distintas ênfases ou olhares que se lançam sobre o tema e sobre a narrativa buscam estabelecer um sistema de valores comum entre o enunciador e o enunciatário, de modo que a preocupação do enunciador não gira 
em torno da "verdade", mas do "dizer-verdadeiro" em cada lugar, para cada público - o que significa estabelecer um regime de crença, pois a atribuição de competência semântica é a primeira barreira a ser vencida para que se possa colocar em curso as estratégias de manipulação propriamente ditas.

Com isso, observamos prevalecer nessas produções a modalização pelo querer: no caso dos teasears, as peças informam sobre o tema a ser abordado, instigando a curiosidade sem revelar detalhes da história a ser contada, as projeções do nível narrativo; já no caso dos trailers, tais projeções passam a ser contempladas no material de divulgação, mas não por completo. Pouco a pouco, tais ações vão levando o enunciatário a um estado de curiosidade, modulado por um "clímax de intensidade e por um máximo de extensidade - um desejo irrefreável de saber tudo" (FIORIN, 2007, p. 13). Um "querer-saber" conduzindo o sujeito a um "querer-fazer", isto é, entrar em conjunção com o produto audiovisual a fim de satisfazer-se - o que significa adesão por assinatura.

Nas vinhetas, observamos que as peças promovem a série Narcos, mas, sobretudo, promovem a marca Netflix. Para cumprir essa dupla proposta, são utilizados recursos intertextuais, interdiscursivos e autorreflexivos ou metalinguísticos. Nesses casos, as modalidades que prevalecem no fazer persuasivo do enunciador sobre o enunciatário, por construções que buscam a identificação do público com determinados actantes, são: as do "dever-fazer", por criar para aquele que não sabe o que é Netflix e não é assinante de seus serviços uma imagem negativa, desconectada do tempo e da sociedade em que vivemos; do "poder-fazer", que gira em torno da questão finan- 
ceira ou do baixo valor cobrado pela mensalidade; e do "saber-fazer", em que se busca instrumentalizar o enunciatário para a fruição dos conteúdos de vídeo por demanda, como funciona o sistema por assinatura e quais são os recursos disponíveis ao usuário.

De maneira que a instância da enunciação se esforça em comunicar ao público todas as competências necessárias - virtualizantes e atualizantes - a fim de que ele realize a sua performance e entre em conjunção com o objeto de valor proposto, a assinatura de vídeos sob demanda da Netflix. Modalizado pelo querer, dever, poder e saber, tornam-se grande as chances de que o enunciatário realize o percurso a ele estipulado. Os dados que trouxemos no início do artigo, em que o valor da Netflix (US\$32,9 bilhões) chega a superar o da terceira maior emissora de televisão aberta do mundo, a CBS (US\$30,6 bilhões), com a conquista de 62,3 milhões de assinantes em 2015, indica que as estratégias de manipulação utilizadas pela empresa têm sido bem-sucedidas, levando-a a entrar em conjunção com seu próprio objeto de valor, o êxito financeiro.

\section{Referências}

CALBUCCl, E. Modalidade, paixão, aspecto. In: Estudos Semióticos, v. 5, n. 2, p. 70-78. ISSN 1980-4016. São Paulo, 2009.

CANO, J. R. O riso sério: um estudo sobre a paródia. In: Cadernos de Pós-graduação em Letras, v. 3, n. 1, p. 83-89. São Paulo: Mackenzie, 2004.

FIORIN, J. L. Semiótica das paixões: o ressentimento. In: Alfa. São Paulo, 2007.

GREIMAS, A. J. Sobre o sentido II - Ensaios semióticos. Trad. Dilson Ferreira da Cruz. São Paulo: Edusp, 2014. 
GREIMAS; A. J.;COURTÉS, J. Dicionário de semiótica. Trad. Alceu Dias Lima et. all. São Paulo: Cultrix, 1979.

HUTCHEON, L. Uma teoria da paródia. Lisboa: Edições 70, 1989.

JAKOBSON, R. Linguística e comunicação. Trad. Izidora Blikstein e José Paulo Paes. São Paulo: Cultrix, 2007.

MICHAELIS UOL. Dicionário online. Disponível em:www.michaelis.uol. com.br.

MOURA, G. B. de. Televisão quando e onde quiser. A adesão ao vídeo on demand pelas emissoras de TV aberta do Brasil. Monografia. Departamento de Comunicação Social - Decom - Curso de Comunicação Social (Jornalismo). João Pessoa, 2015. Disponível em: http://www.ccta.ufpb.br/cj/contents/tcc/monografia-gefferson-borges-televisao-quando-e-onde-quiser-a-adesao-ao-video-on-demand-pelas-emissoras-de-tv-aberta-do-brasil-ufpb-2015-1.pdf. Acesso em: 14 de setembro de 2016.

SCHIAVONI, J. E. Vinheta de TV: tipos, usos e funções. Bauru: Mediaworks, 2015.

SILVA, Paula Brand; SILVA, Thayná Teixeira da. Proposição de modelo de negócios para entrada de $m$ novo player no mercado de vídeo on demand. Monografia. Rio de Janeiro: UFRJ/Escola Politécnica, 2013, 72 p. Disponível em: http://monografias.poli.ufrj.br/monografias/monopoli10008474.pdf. Acesso em: 14 de setembro de 2016.

\section{Jaqueline Esther Schiavoni}

Jornalista, doutora em Meios e Processos Audiovisuais (ECA-USP). Membro pesquisadora do GEA-Unesp (CNPq). E-mail: jeschiavoni@ yahoo.com.br.

Currículo Lattes: http://buscatextual.cnpq.br/buscatextual/visualizacv.do? id=K4756319D4 